\title{
Expression of tumor necrosis factor receptor-assicated factor 4 correlates with expression of Girdin and promotes nuclear translocation of Girdin in breast cancer
}

\author{
AILIAN WANG ${ }^{1}$, JIAN WANG $^{1}$, LILI SUN ${ }^{1}$, JUAN JIN $^{2}$, HUAYAN REN ${ }^{1}$, \\ FAN YANG $^{1}$, KEXIN DIAO $^{1}$, MINJIE WEI ${ }^{3}$ and XIAOYI MI ${ }^{1}$ \\ ${ }^{1}$ Department of Pathology, First Affiliated Hospital and College of Basic Medical Sciences, China Medical University, \\ Shenyang, Liaoning 110001; ${ }^{2}$ Department of Pathology, Shaanxi Baoji Centre Hospital, Baoji, Shaanxi 721008; \\ ${ }^{3}$ Department of Pharmacology, Pharmaceutical College, China Medical University, Shenyang, \\ Liaoning 110001, P.R. China
}

Received December 5, 2013; Accepted August 1, 2014

DOI: $10.3892 / \mathrm{mmr} .2015 .3211$

\begin{abstract}
Overexpression of tumor necrosis factor receptor-associated factor 4 (TRAF4) has been reported in several human malignancies; however its association with Girdin in breast cancer is unclear. The aim of the present study was to analyze the correlation, expression and nuclear and cytoplasmic localizations of TRAF4 and Girdin in breast cancer tissues. Tissue samples from 38 patients with breast cancer, the MCF-10A normal mammary epithelial cell line, the MCF-7 estrogen-receptor (ER)-positive and MDA-MB-231 ER-negative breast cancer cell lines were used in the present study. The results demonstrated that cytoplasmic expression of TRAF4 was positively correlated with cytoplasmic expression of Girdin. Furthermore, coexpression of TRAF4 and Girdin was highest in tissue samples from patients with lymph node metastases. Girdin was observed to be predominantly expressed in the cytoplasm of breast cancer cells; however TRAF4 promoted its translocation to the nucleus. These findings suggest that cytoplasmic expression of TRAF4 may be a novel potential marker for cell migration in breast cancer.
\end{abstract}

\section{Introduction}

Members of the tumor necrosis factor receptor-associated factor (TRAF) family are overexpressed in numerous types of human cancer and are involved in the activation of multiple signal transduction pathways (1). TRAF4 has

Correspondence to: Dr Xiaoyi Mi, Department of Pathology, First Affiliated Hospital and College of Basic Medical Sciences, China Medical University, North 2nd Road 92, Heping Ward, Shenyang, Liaoning 110001, P.R. China

E-mail: mixiaoyi2005@163.com

Key words: TRAF4, girdin, breast cancer, nuclear translocation, estrogen receptor been demonstrated to promote Smurf1-mediated ubiquitination-dependent cell migration, transforming growth factor (TGF)- $\beta$ receptor signaling and breast cancer metastasis $(2,3)$. It also serves as a critical molecule in Akt activation in lung cancer (4). The Akt pathway has been indicated to modulate TRAF4-mediated inhibition of Glut1 and HK2 expression, leading to impairment of glucose metabolism (4). Although overexpression of TRAF4 has been reported in several types of carcinoma (5), its biological function in tumorigenesis remains to be elucidated.

Girders of actin filament (Girdin) is activated by Akt-induced phosphorylation in response to epidermal growth factor receptor (EGFR) signaling and insulin-like growth factor 1 stimulation (6,7); the Girdin-Gai molecular complex binds to EGFR to determine whether cells migrate or proliferate (8). Girdin has been observed to facilitate cell migration and metastasis in breast and colon cancer (9-11), and its expression has been correlated with histological grade and distant metastasis in breast cancer (12).

TRAF4 regulates a set of cancer-related genes that are involved in biological processes such as migration, invasion, metastasis and angiogenesis, in which Girdin is strongly implicated (13). Therefore, it is considered as the member of the TRAF family that may influence Girdin. TRAF4 and Girdin have been implicated in the phosphatidylinositol 3-kinase (PI3-K)/Akt signal transduction pathway, which is central to cancer progression (14). TRAF4 was reported to activate Akt, a pivotal cell survival kinase, through ubiquitination in lung cancer. In addition, TRAF4 was identified to mediate activation of nuclear factor $-\kappa \mathrm{B}(\mathrm{NF}-\kappa \mathrm{B})$ through glucocorticoid-induced tumor necrosis factor receptor (15). The p65 and p50 forms of NF- $\mathrm{BB}$ interact physically with signal transducer and activator of transcription-3 (STAT3), facilitating $\mathrm{NF}-\kappa \mathrm{B}$ recruitment to STAT3 promoters (16). Girdin was previously demonstrated to be a direct target of STAT3 (17), suggesting that TRAF4 may influence Girdin through NF- $\kappa$ B-mediated STAT3 activity.

Based on these observations, the present study hypothesized that TRAF4 and Girdin cooperate in tumor invasion 
and metastasis. To test this hypothesis, the expression status of Girdin in breast cancer cells and its association with TRAF4 was investigated. The results may aid in the development of novel methods for the management of breast cancer treatment.

\section{Materials and methods}

Patients and tissue samples. Tissue samples were collected from 38 patients who had been diagnosed with breast cancer between 1998 and 2005 and had presented to the First Affiliated Hospital of China Medical University (Shenyang, China). None of the patients had received radiotherapy or chemotherapy prior to surgical resection, and all the patients were treated with routine chemotherapy subsequent to the operation. The median age of the patients was 58 years (range: 37-72 years). The tissue specimens were independently reviewed by three pathologists and the diagnoses were confirmed according to the World Health Organization criteria for the classification of breast cancer. The study received ethical approval from and was conducted according to the Regulations of the Institutional Review Board of the China Medical University. Informed consent was obtained from all the patients enrolled in the study, or their next of kin.

Reagents and antibodies. HEPES-buffered Dulbecco's modified Eagle's medium (H-DMEM), Leibovitz's L-15 medium and fetal bovine serum (FBS) were purchased from Gibco Life Technologies (Grand Island, NY, USA). Bovine serum albumin (BSA) and Triton X-100 were purchased from Beyotime Institute of Biotechnology (Haimen, China).

The following primary antibodies were used: Anti-Girdin (human), anti-TRAF4 (rabbit), anti- $\beta$-actin (mouse) and anti-lamin B1 (goat; Santa Cruz Biotechnology, Texas, TX, USA). Anti-mouse and anti-rabbit IgG secondary antibodies conjugated with horseradish peroxidase were purchased from Santa Cruz Biotechnology. Biotinylated secondary antibodies (anti-mouse/rabbit, Fuzhou Maixin Biotechnology Development Co., Ltd., Fuzhou, China) were used for immunohistochemistry and fluorescein isothiocyanate (FITC)/tetramethylrhodamine (TRITC)-conjugated secondary antibodies (anti-rabbit and anti-mouse, respectively; Santa Cruz Biotechnology) were used for immunofluorescence.

Cell lines and cell culture. The non-tumorigenic mammary epithelial cell line MCF-10A, and the breast cancer cell lines MCF-7 and MDA-MB-231 were obtained from the American Type Culture Collection (Manassas, VA, USA).

MCF-7 cells and MCF-10A cells were grown in H-DMEM medium and MDA-MB-231 cells were grown in Leibovitz's L-15 medium. All culture media contained 10\% FBS supplemented with $100 \mathrm{IU} / \mathrm{ml}$ penicillin and $100 \mu \mathrm{g} / \mathrm{ml}$ streptomycin (Invitrogen Life Technologies, New York, NY, USA). The cells were cultured at $37^{\circ} \mathrm{C}$ in a humidified atmosphere with $5 \% \mathrm{CO}_{2}$.

Plasmids and transfection. The pcDNA3-TRAF4 plasmid (plasmid 16375) was purchased from Addgene (Cambridge, MA, USA). MCF-7 cells were transiently transfected using Attractene Transfection Reagent or HiPerFect Transfection
Reagent (Qiagen, Hilden, Germany) according to the manufacturer's instructions. Untransfected MCF-7 cells and cells transfected with empty plasmid were used as negative controls. Lamin B1 was used as a nuclear internal control and $\beta$-actin was used as a cytoplasmic internal control.

Preparation of nuclear and cytoplasmic extracts. To detect the cellular localization of Girdin, nuclear and cytoplasmic fractions were isolated using the Pierce NE-PER Nuclear and Cytoplasmic Extraction Reagents (Thermo Fisher Scientific; Rockford, IL, USA) according to the manufacturer's instructions.

Immunohistochemistry. The anti-Girdin and anti-TRAF4 primary antibodies (1:100) were incubated at $4^{\circ} \mathrm{C}$ overnight, followed by incubation with biotinylated secondary antibodies at $37^{\circ} \mathrm{C}$ for $20 \mathrm{~min}$. The peroxidase reaction was developed with DAB (Fuzhou Maixin Biotechnology Development Co., Ltd.). Hematoxylin was used as a counterstain, and the sections were dehydrated in alcohol prior to being mounted on slides. The primary antibodies were replaced with phosphate-buffered saline (PBS) for the negative control.

Western blot analysis. Proteins were extracted using radioimmunoprecipitation assay (RIPA) buffer containing a protease and phosphatase inhibitor cocktail (Beyotime, Shanghai, China). The protein concentrations were determined using a Bicinchoninic Acid Protein Assay kit (Beyotime Institute of Biotechnology). Equal amounts of protein from the samples were separated by $8 \%$ SDS-PAGE and transferred to polyvinylidene fluoride membranes (EMD Millipore; Bedford, MA, USA). The membranes were blocked with 5\% non-fat milk in PBS, prior to incubation with the primary antibodies against Girdin (1:200), TRAF4 (1:200), $\beta$-actin $(1: 1,000)$ or lamin B1 (1:500). The membranes were then incubated with the respective secondary antibody $(1: 2,000)$ and the protein bands were imaged using Pierce ECL Western Blotting Substrate (Thermo Fisher Scientific). The protein expression was quantified using ImageJ (National Institute of Health, Bethesda, MD, USA).

Immunofluorescence. The cells were seeded in Nunc 24-well plates (Thermo Fisher Scientific) at a density of $2 \times 10^{4}$ cells/well, fixed with $4 \%$ paraformaldehyde (Invitrogen Life Technologies) and permeabilized with $0.2 \%$ Triton X-100. Subsequent to blocking with 5\% BSA in PBS, the cells were incubated with either Girdin (1:50) or TRAF4 (1:50) primary antibody at $4{ }^{\circ} \mathrm{C}$ overnight, followed by incubation with a FITC/TRITC-conjugated secondary antibody (1:50; Santa Cruz Biotechnology) for $2 \mathrm{~h}$ at room temperature. The nuclei were stained with DAPI (Beyotime Institute of Biotechnology) and the cells were examined under a Leica DM5500 B microscope (Leica Microsystems GmbH, Wetzlar, Germany).

Statistical analysis. All statistical analyses were performed using SPSS software, version 17.0 (SPSS, Inc., Chicago, IL, USA). Pearson's $\chi^{2}$ test was used to determine correlations between TRAF4/Girdin coexpression and clinicopathological factors. Spearman's correlation test was used to determine 
the association between TRAF4 and Girdin expression (positive vs. negative). Independent-samples t-test was used to compare data between two groups. One-way analysis of variance and Bonferroni correction were used to compare data between three or more groups. The data are expressed as the means \pm standard deviation. $\mathrm{P}<0.05$ was considered to indicate a statistically significant difference.

\section{Results}

Overexpression of TRAF4 correlates with Girdin expression in the cytoplasm of breast carcinoma tissues. Immunohistochemical analysis revealed that the TRAF4 and Girdin proteins were expressed in the cytoplasm and nuclei of cells from breast cancer tissues. The staining patterns indicated that $35 / 38(92.11 \%)$ samples stained positive for TRAF4 protein and 26/38 (68.42\%) samples stained positive for Girdin protein. In addition, 14/38 (36.84\%) samples presented coexpression of the TRAF4 and Girdin proteins (Fig. 1; Table I). However, more intense staining patterns were observed in invasive ductal carcinoma (IDC) tissue samples compared with ductal carcinoma in situ (DCIS) tissue samples, and TRAF4/Girdin coexpression was significantly correlated with lymph node metastasis in tissue samples from patients.

Further analyses indicated that the coexpression of TRAF4 and Girdin proteins was significantly higher in c-erbB2-negative cases as compared with c-erbB2-positive cases (66.67 vs. 17.39\%). By contrast, no significant differences in coexpression rates were observed between samples that were positive or negative for the estrogen receptor, progesterone receptor or p53 (Table I).

The association between the positive and negative cytoplasmic expression rates of TRAF4 and Girdin in breast cancer cells are summarized in Table II. There were a total of 35 samples displaying positive cytoplasmic expression of TRAF4 protein. Of these, 14 samples were Girdin-negative while 21 were Girdin-positive. By contrast, 3 samples were TRAF4-negative, all of which were Girdin-negative. These observations demonstrated that the expression of Girdin in the cytoplasm of breast cancer tissues was positively correlated with expression of TRAF4 $(\mathrm{P}<0.05)$.

Expression patterns of Girdin protein in breast cancer cell lines. The levels of Girdin protein were compared in three breast cell lines: MCF-10A, normal human breast epithelia; MCF-7, ER-positive weakly invasive luminal A breast cancer cells (18); and MDA-MB-231,ER-negative highly proliferative and invasive triple-negative breast cancer cells (18). Western blot analysis and relative quantification indicated that the Girdin protein was highly expressed in MDA-MB-231 and MCF-7 breast cancer cell lines; whereas only trace amounts were observed in normal MCF-10A breast cells (Fig. 2A).

The cell extracts were separated into cytoplasmic and nuclear fractions, and the relative abundance of Girdin in the fractions were analyzed by Western blotting (Fig. 2B). In agreement with a previous observation (7), Girdin was more strongly expressed in c-erbB2-positive tumor tissues than c-erbB2-negative tissues, and the western blotting results demonstrated that Girdin was more highly expressed in the
Table I. Correlations between TRAF4 and Girdin coexpression and clinicopathological features.

\begin{tabular}{|c|c|c|c|c|}
\hline \multirow[b]{2}{*}{ Feature } & \multirow[b]{2}{*}{$\mathrm{N}$} & \multicolumn{2}{|c|}{$\begin{array}{l}\text { TRAF4/Girdin } \\
\text { coexpression }\end{array}$} & \multirow[b]{2}{*}{$\chi^{2}$} \\
\hline & & Negative & Positive & \\
\hline \multicolumn{5}{|c|}{ Age (years) } \\
\hline$\leq 50$ & 17 & 12 & 5 & 0.73 \\
\hline$>50$ & 21 & 12 & 9 & \\
\hline \multicolumn{5}{|c|}{ Histology-type } \\
\hline DCIS & 8 & 8 & 0 & $5.911^{\mathrm{a}}$ \\
\hline IDC & 30 & 16 & 14 & \\
\hline \multicolumn{5}{|c|}{ Tumor size $(\mathrm{cm})$} \\
\hline$\leq 3.0$ & 14 & 9 & 6 & 0.106 \\
\hline$>3.0$ & 23 & 15 & 8 & \\
\hline \multicolumn{5}{|l|}{ LNM } \\
\hline negative & 24 & 18 & 6 & $4.786^{\mathrm{a}}$ \\
\hline positive & 13 & 5 & 8 & \\
\hline \multicolumn{5}{|l|}{ ER } \\
\hline negative & 30 & 20 & 10 & 0.754 \\
\hline positive & 8 & 4 & 4 & \\
\hline \multicolumn{5}{|l|}{ PR } \\
\hline negative & 29 & 18 & 11 & 0.062 \\
\hline positive & 9 & 6 & 3 & \\
\hline \multicolumn{5}{|l|}{ CerbB-2 } \\
\hline negative & 15 & 5 & 10 & $9.474^{\mathrm{a}}$ \\
\hline positive & 23 & 19 & 4 & \\
\hline \multicolumn{5}{|l|}{ P53 } \\
\hline negative & 15 & 9 & 6 & 0.106 \\
\hline positive & 23 & 15 & 8 & \\
\hline
\end{tabular}

${ }^{\mathrm{a}} \mathrm{P}<0.05$, correlation between feature and TRAF4/Girdin coexpression. DCIS, ductal carcinoma in situ; IDC, invasive ductal carcinoma; LNM, lymph node metastasis; ER, estrogen receptor; PR, progesterone receptor.

Table II. Association between cytoplasmic TRAF4 and Girdin expression in breast cancer tissue.

\begin{tabular}{lccc}
\hline & \multicolumn{2}{c}{ Girdin expression } & \\
\cline { 2 - 3 } & negative & positive & $\chi^{2}$ \\
\hline $\begin{array}{l}\text { TRAF4 expression } \\
\text { negative }\end{array}$ & 3 & & \\
positive & 14 & 21 & $4.024^{\mathrm{a}}$ \\
\hline
\end{tabular}

${ }^{\mathrm{a}} \mathrm{P}<0.05$

cytoplasm of the weakly invasive MCF-7 cells than in the strongly invasive MDA-MB-231 cells.

The expression and localization of Girdin protein in MCF-7 and MDA-MB-231 breast cancer cells was evaluated 
A

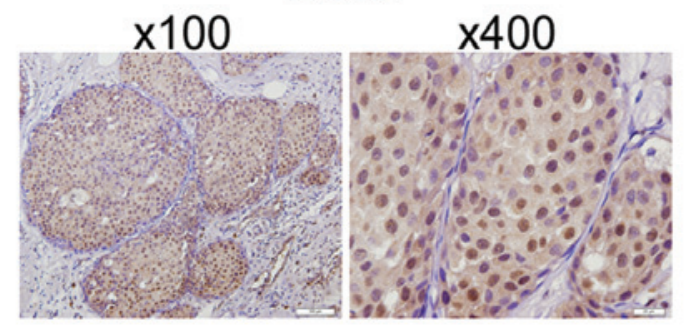

C

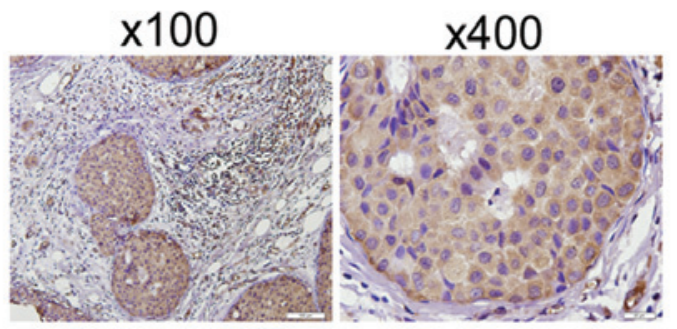

B

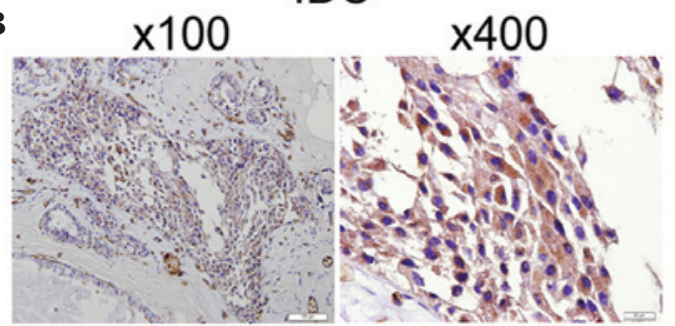

D

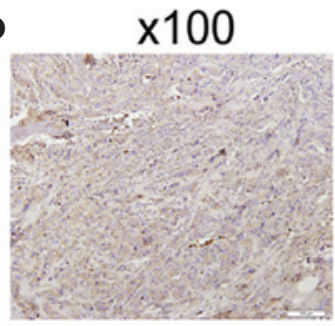

IDC

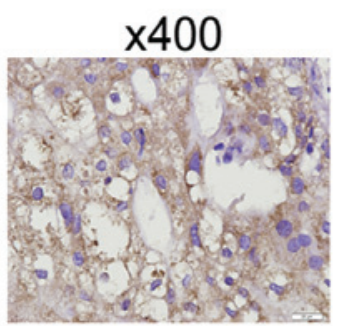

TRAF4

Girdin

Figure 1. Immunohistochemical analyses of TRAF4 and Girdin in breast cancer tissue. Brown staining indicates positive expression of (A and B) TRAF4 and (C and D) Girdin protein. The staining patterns indicate that TRAF4 and Girdin are located in the cytoplasm and nuclei of breast cancer tissue. Expression levels of TRAF4 in (A) DCIS and (B) IDC tissue samples and Girdin in (C) DCIS and (D) IDC tissue samples. DCIS, ductal carcinoma in situ; IDC, invasive ductal carcinoma.

A

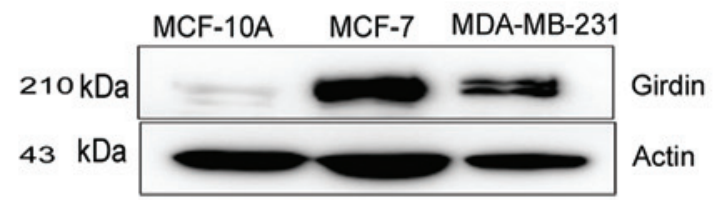

B

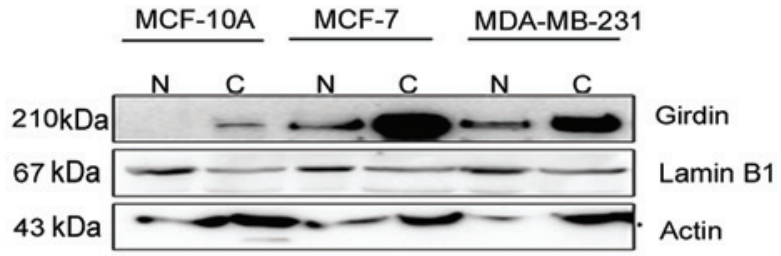

C
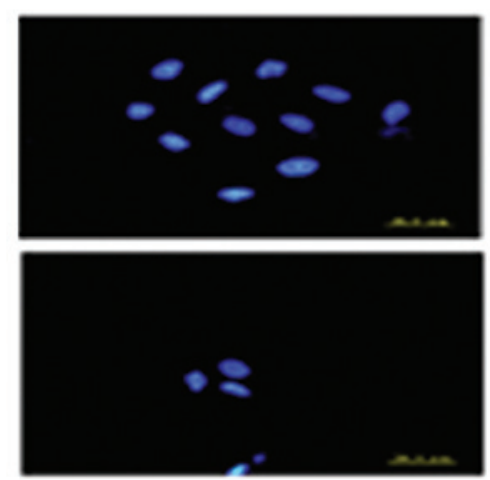

Girdin
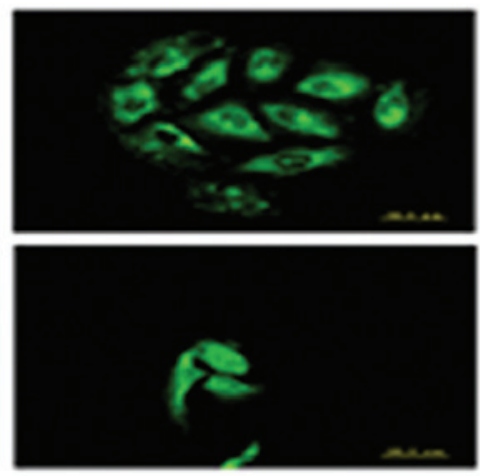
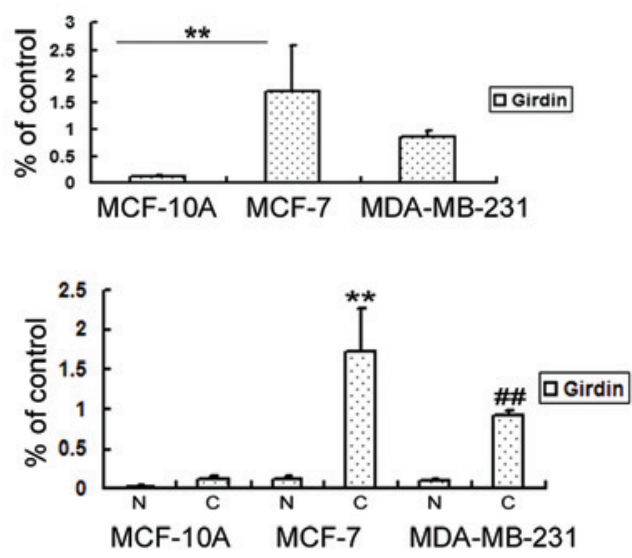

Figure 2. Girdin expression in normal and tumor breast cells. (A) Western blot analysis indicating the levels of Girdin protein in MCF-10A, MCF-7 and MDA-MB-231 cells. Actin was used as an internal control. Relative protein levels are presented as the mean \pm standard deviation $(\mathrm{n}=3)$; ${ }^{*} \mathrm{P}<0.05$ and ${ }^{* *} \mathrm{P}<0.01$, MCF-7 vs. MCF-10A. (B) Western blot analysis indicating the levels of Girdin protein in cytoplasmic and nuclear fractions of MCF-10A, MCF-7 and MDA-MB-231 cells. Lamin B1 was used as a nuclear control; $\beta$-actin as a cytoplasmic control. Relative protein levels are presented as the mean \pm standard deviation ( $\mathrm{n}=3$ ); ${ }^{*} \mathrm{P}<0.05$ and ${ }^{* *} \mathrm{P}<0.01$, cytoplasmic in MCF-7 cells vs. cytoplasmic and nuclear in MCF-10A and MDA-MB-231 cells; and nuclear in MCF-7 cells; ${ }^{~} \mathrm{P}<0.05$ and ${ }^{\# \#} \mathrm{P}<0.01$, cytoplasmic in MDA-MB-231 cells vs. cytoplasmic and nuclear in MCF-10A and MCF-7 cells; and nuclear in MDA-MB-231 cells. (C) Indirect immunofluorescence staining intensity indicates the expression levels of Girdin protein in MCF-7 and MDA-MB-231 breast cancer cells. Green fluorescence, Girdin; blue fluorescence, DAPI-stained nuclei. Magnification, x400. 


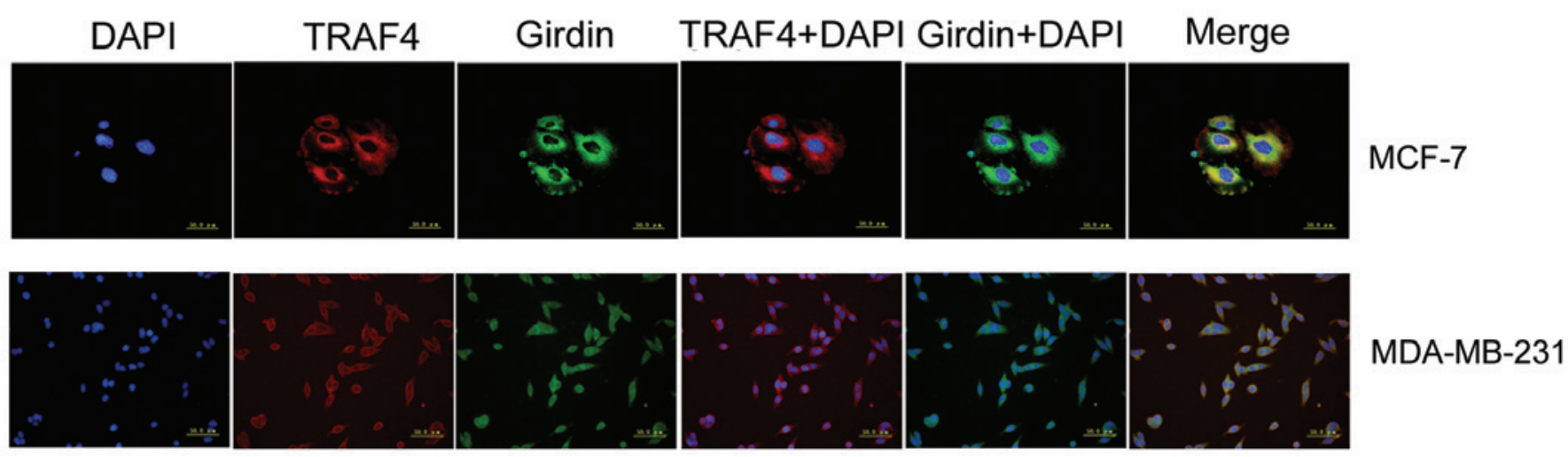

Figure 3. TRAF4 and Girdin are colocalized in the cytoplasm of breast cancer cells. Immunofluorescence staining patterns exhibit the colocalization of TRAF4 and Girdin in MCF-7 and MDA-MB-231 breast cancer cells. Green fluorescence, Girdin; red fluorescence, TRAF4; blue fluorescence, DAPI-stained nuclei. Magnification, x400.

A
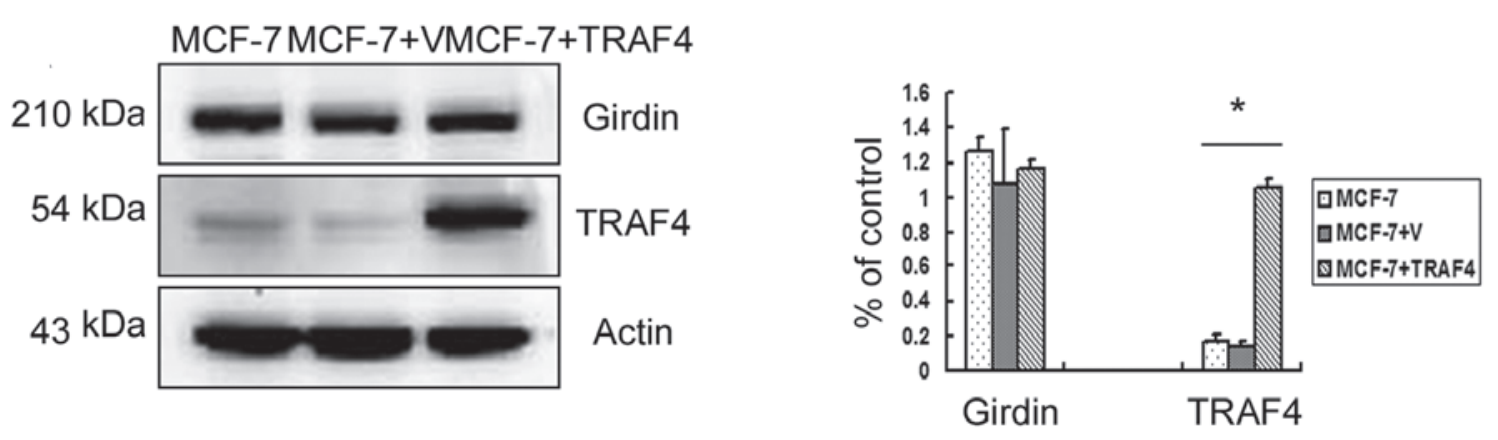

B MCF-7+V MCF-7+TRAF4
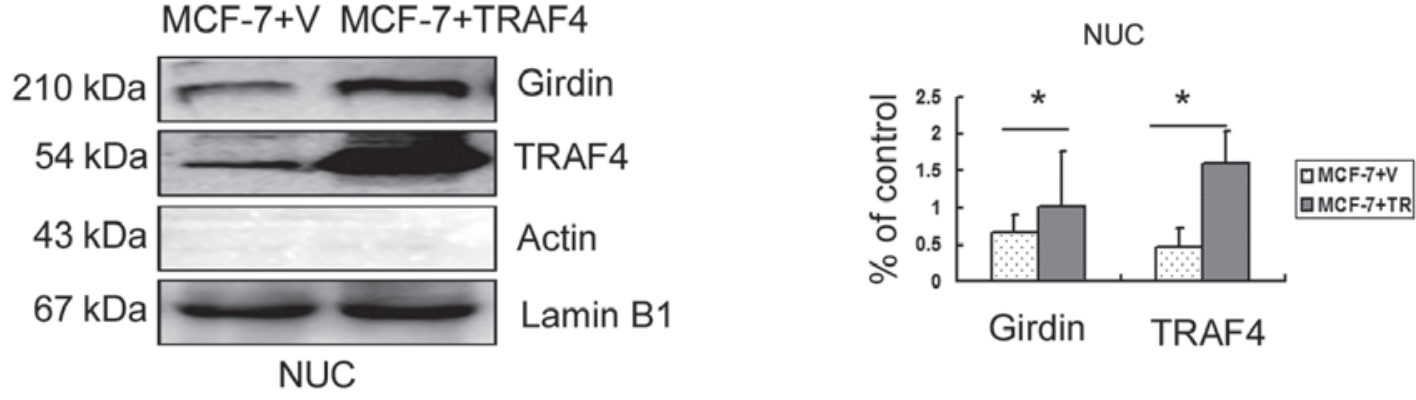

C
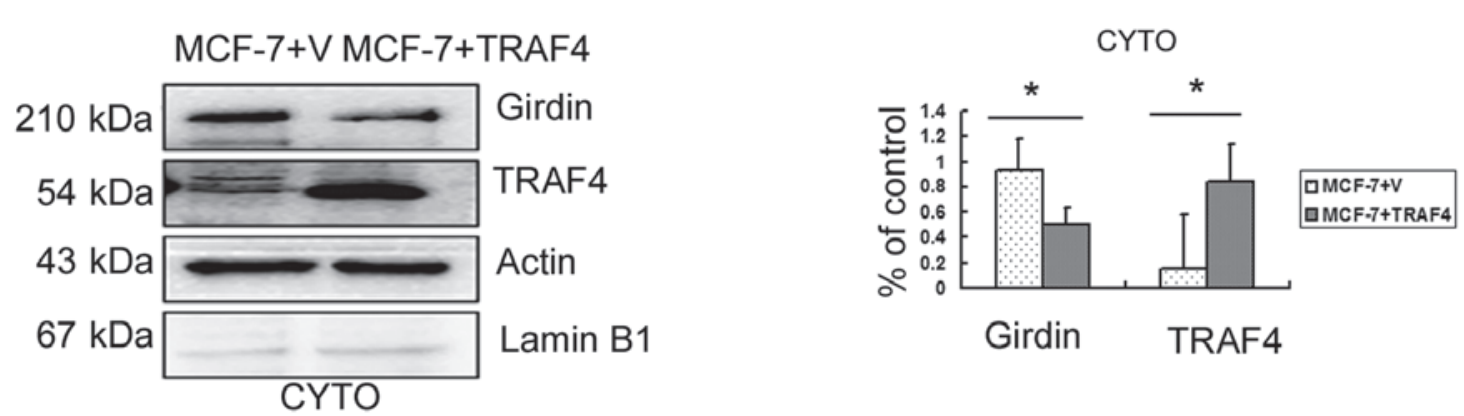

Figure 4. TRAF4 promotes translocation of Girdin from the cytoplasm to the nucleus in MCF-7 breast cancer cells. (A) Western blot analysis demonstrates that the overall expression level of Girdin in MCF-7+TRAF4 cells was not significantly higher than the levels in MCF-7+V cells. (B) Western blot analysis demonstrates nuclear expression levels of Girdin protein in MCF-7+TRAF4 and in MCF-7+V cells. Lamin B1 was used as an internal nuclear control. (C) Western blot analysis indicates cytoplasmic expression levels of Girdin protein in MCF-7+TRAF4 and MCF-7+V cells, and $\beta$-actin was used as an internal cytoplasmic control. Relative protein levels are presented as the mean \pm standard deviation $(\mathrm{n}=3)$; ${ }^{*} \mathrm{P}<0.05$ and ${ }^{* *} \mathrm{P}<0.01, \mathrm{MCF}-7+\mathrm{TRAF} 4$ vs. MCF-7+V. MCF-7, normal controls; MCF-7+TRAF4, TRAF4-overexpressing MCF-7 cells; MCF-7+V, vector control. 
by indirect immunofluorescence (Fig. 2C). The fluorescent staining patterns indicated that Girdin was mainly localized in the cytoplasm in MCF-7 and MDA-MB-231 cells; however it was also detectable in the nuclei of the MDA-MB-231 cells. These observations are consistent with the immunohistochemical and immunofluorescence results (Fig. 1 and Fig. 3, respectively), which indicated that Girdin was mainly localized in the cytoplasm in breast cancer tissues, with no significant staining in the nuclei.

TRAF4 and Girdin colocalize in the cytoplasm of breast cancer cells. Immunohistochemistry indicated that cytoplasmic overexpression of TRAF4 and Girdin were positively correlated in breast cancer cells. In order to verify these results, immunofluorescence experiments were performed. These demonstrated that TRAF4 and Girdin proteins colocalized in the cytoplasm of MCF-7 and MDA-MB-231 breast cancer cells (Fig. 3).

TRAF4 promotes the translocation of Girdin from the cytoplasm to the nuclei in breast cancer cells. Previous studies had demonstrated that TRAF4 was essential for the migration of normal mammary epithelial and breast cancer cells $(2,3)$; Girdin has also been implicated in migration and metastasis (9-11). In order to determine whether the molecular mechanisms of TRAF4-induced migration involved the regulation of Girdin expression, TRAF4 was overexpressed in the weakly invasive MCF-7 breast cancer cell line. However, no significant increase in the overall Girdin protein levels were observed compared with untransfected cells or empty vector controls ( $\mathrm{P}>0.05$; Fig. 4A). Therefore, Girdin protein levels in the cytoplasm and nuclei of transfected MCF-7 cells were analyzed individually by western blotting. The results revealed that overexpression of TRAF4 significantly reduced cytoplasmic expression of Girdin $(\mathrm{P}<0.05)$ but significantly increased its nuclear expression $(\mathrm{P}<0.05$; Fig. $4 \mathrm{~B}$ and $\mathrm{C})$.

\section{Discussion}

Girdin is an actin-binding protein that is essential in remodeling the actin cytoskeleton (19). It is also important for cell motility and is implicated in tumor progression (13). TRAF4 is required for Akt Ub-Lys63 ubiquitination (4), which is essential for Akt activity $(20,21)$. TRAF4 is also associated with $\mathrm{NF}-\kappa \mathrm{B}$ activation, and thereby STAT3 transcription. As Girdin is activated by Akt and has been identified as a direct target of STAT3 (16), TRAF4 may potentially influence Girdin via the Akt signaling pathway. However, the association between TRAF4 and Girdin and the underlying mechanisms of action remain to be established.

The current study demonstrated that the cytoplasmic overexpression of TRAF4 in breast cancer tissues was positively correlated with cytoplasmic expression of Girdin. In addition, it was observed that TRAF4 was more highly expressed in the cytoplasm of breast cancer cells than in normal breast cells; that TRAF4 and Girdin were more highly expressed in IDC tissue samples than in DCIS tissue samples; and that coexpression of TRAF4 and Girdin was higher in tissue samples taken from patients with lymph node metastases than those without metastasis.
A previous study reported that Girdin expression was significantly correlated with c-erbB2 and Ki67 expression, by demonstrating that Girdin expression was significantly higher in c-erbB2- and Ki67-positive cases than in c-erbB2- and Ki67-negative cases (12). In the current study, it was observed that TRAF4 and Girdin coexpression was significantly higher in tissues from c-erbB2-negative cases than in tissues from c-erbB2-positive cases. However, further analysis is required to verify this finding.

Although Girdin expression has previously been identified in MDA-MB-231 breast cancer cells $(9,17)$, the expression levels were not compared with normal breast cell lines or other breast cancer cell lines. In the current study, Girdin expression levels were analyzed in normal MCF-10A breast cells and ER-positive MCF-7 breast cancer cells, in addition to ER-negative MDA-MB-231 cells. It was demonstrated that the expression levels of Girdin were lower in normal breast cells compared to breast cancer cells $(\mathrm{P}<0.01)$, and were higher in ER-positive MCF-7 cells than in ER-negative MDA-MB-231 cells. However the difference between the two breast cancer cell lines was not statistically significant.

Consistent with a previous study that examined immunohistochemical staining patterns of Girdin in breast cancer tissues (7), the immunofluorescence observations of the present study revealed that Girdin was mainly localized in the cytoplasm of breast cancer cells. To further explore the association between TRAF4 and Girdin in breast cancer, TRAF4 was overexpressed in MCF-7 cells to determine the effect on cytoplasmic and nuclear expression of Girdin. These results demonstrated that the overexpression of TRAF4 promoted translocation of Girdin from the cytoplasm to the nuclei in breast cancer cells. This finding remains to be verified in the highly invasive MDA-MB-231 cell line.

In conclusion, the present study demonstrated that cytoplasmic expression of TRAF4 was positively correlated with cytoplasmic expression of Girdin in breast cancer cells, and that the coexpression of TRAF4 and Girdin was highest in patients with lymph node metastases. Furthermore, it was observed that Girdin was predominantly expressed in the cytoplasm of breast cancer cells, but that TRAF4 was able to promote its translocation from the cytoplasm to the nucleus. Although the underlying mechanisms remain to be established, the present findings suggest that cytoplasmic expression of TRAF4 is a potential novel marker for migration in breast cancer.

\section{References}

1. Xie P: TRAF molecules in cell signaling and in human diseases. J Mol Signal 8: 7, 2013.

2. Zhang L, Zhou F, García de Vinuesa A, et al: TRAF4 promotes TGF- $\beta$ receptor signaling and drives breast cancer metastasis. Mol Cell 51: 559-572, 2013.

3. Wang X, Jin C, Tang Y, Tang LY and Zhang YE: Ubiquitination of tumor necrosis factor receptor associated factor 4 (TRAF4) by Smad ubiquitination regulatory factor 1 (Smurf1) regulates motility of breast epithelial and cancer cells. J Biol Chem 288: 21784-21792, 2013.

4. Li W, Peng C, Lee MH, et al: TRAF4 is a critical molecule for Akt activation in lung cancer. Cancer Res 73: 6938-6950, 2013.

5. Camilleri-Broët S, Cremer I, Marmey B, et al: TRAF4 overexpression is a common characteristic of human carcinomas. Oncogene 26: 142-147, 2007. 
6. Garcia-Marcos M, Jung BH, Ear J, Cabrera B, Carethers JM and Ghosh P: Expression of GIV/Girdin, a metastasis-related protein, predicts patient survival in colon cancer. FASEB J 25: 590-599, 2011.

7. Ling Y,Jiang P, Cui SP, et al: Clinical implications for Girdin protein expression in breast cancer. Cancer Invest 29: 405-410, 2011.

8. Ghosh P, Garcia-Marcos M and Farquhar MG: GIV/Girdin is a rheostat that fine-tunes growth factor signals during tumor progression. Cell Adh Migr 5: 237-248, 2011.

9. Jiang P, Enomoto A, Jijiwa M, et al: An actin-binding protein Girdin regulates the motility of breast cancer cells. Cancer Res 68: 1310-1318, 2008

10. Jun BY, Kim SW, Jung CK, et al: Expression of girdin in human colorectal cancer and its association with tumor progression. Dis Colon Rectum 56: 51-57, 2013.

11. Ghosh P, Garcia-Marcos M, Bornheimer SJ and Farquhar MG: Activation of Galphai3 triggers cell migration via regulation of GIV. J Cell Biol 182: 381-393, 2008.

12. Liu C, Zhang Y, Xu H, et al: Girdin protein: a new potential distant metastasis predictor of breast cancer. Med Oncol 29 1554-1560, 2012.

13. Enomoto A, Ping J and Takahashi M: Girdin, a novel actin-binding protein, and its family of proteins possess versatile functions in the Akt and Wnt signaling pathways. Ann NY Acad Sci 1086: $169-184,2006$

14. Weng L, Enomoto A, Ishida-Takagishi M, Asai $\mathrm{N}$ and Takahashi M: Girding for migratory cues: roles of the Akt substrate Girdin in cancer progression and angiogenesis. Cancer Sci 101: 836-842, 2010.
15. Esparza EM and Arch RH: TRAF4 functions as an intermediate of GITR-induced NF-kappaB activation. Cell Mol Life Sci 61: 3087-3092, 2004

16. Yang J, Liao X, Agarwal MK, Barnes L, Auron PE and Stark GR: Unphosphorylated STAT3 accumulates in response to IL-6 and activates transcription by binding to NFkappaB. Genes Dev 21: 1396-1408, 2007.

17. Dunkel Y, Ong A, Notani D, Mittal Y,Lam M, Mi X and Ghosh P: STAT3 protein up-regulates $\mathrm{G} \alpha$-interacting vesicle-associated protein (GIV)/Girdin expression, and GIV enhances STAT3 activation in a positive feedback loop during wound healing and tumor invasion/metastasis. J Biol Chem 287: 41667-41683, 2012

18. Lautenschlaeger T, Perry J, Peereboom D, et al: In vitro study of combined cilengitide and radiation treatment in breast cancer cell lines. Radiat Oncol 8: 246, 2013.

19. Enomoto A, Murakami H, Asai N, et al: Akt/PKB regulates actin organization and cell motility via Girdin/APE. Dey Cell 9: 389-402, 2005.

20. Yang WL, Wu CY, Wu J and Lin HK: Regulation of Akt signaling activation by ubiquitination. Cell Cycle 9: 487-497, 2010.

21. Lin K: The Akt DUBbed InAktive. Sci Signal 6: pe1, 2013. 